\title{
INFLUENZA PANDEMICS DEPEND ON CERTAIN ANTICYCLONIC WEATHER CONDITIONS FOR THEIR DEVELOPMENT
}

\author{
C. M. RICHTER, M.D. \\ SAN FRANCISCO \\ SYNOPSIS
}

Air pressure records (1826-1920) exhibit the fact that high pressure periods, lasting a number of years, vary with similar periods of low air pressure. Changes in solar activity harmonize with and apparently cause such pressure periods. Influenza pandemics and pneumonia epidemics develop only during high pressure periods. Influenza pandemics of $1890,1891,1918,1919$ and 1920 prove this fact as far as records are obtainable for the Northern Hemisphere and probably also for the Southern Hemisphere. All these epidemics come to a more or less sudden end following the advent of distinctly low air pressure. Records of cities in a highly diversified climate, as, for instance, California represents, prove that no meteorologic element, except air pressure, runs parallel to the development of influenza or pneumonia epidemics. Since it is definitely proven that these epidemics are a function of anticyclonic weather values, we must extend our laboratory work to an investigation of the physics of the atmosphere. The proposition is, whether the atmosphere during those epidemics acts as the carrier of a certain virus, or whether its physicochemical quality, changed during such weather periods, is the cause of influenza.

The relation of climate or weather to health, and especially to the incidence of pneumonia and influenza epidemics, always has been a most difficult problem for the investigator. The people living on the continents experience a climate which changes almost hourly in temperature, humility and other meteorologic elements. There is a constant movement of the air that surrounds us. On the continent of Europe and on the area of the United States the air is generally moving from the West to the East. This movement is subject to a change in its direction; for instance, by the occasional influx of gigantic masses of air, generally coming from a northerly direction, but also descending from considerable height. Such inflowing air may cover the entire continents and assemble there for a number of weeks, without any tendency to resume the easterly direction. As increase of air pressure is necessarily incidental to such air assemblage, and as the mechanical effect of such pressure has been considered negligible, the influence on health of this meteorologic factor has been generally disregarded in favor of tem- 
perature and humidity as the principal factors affecting health. If we scrutinize the foundation for the latter assumption on areas of the continents which are not subject to any material change of temperature and humidity from summer to winter, as for instance, on the coast area of California, from San Francisco to San Diego, it becomes clear that the so-called "cold weather diseases" or respiratory diseases are not a function of temperature and humidity, but are dependent on certain high air pressure conditions. This fact, abundantly proven on such areas, ${ }^{1}$ eliminates temperature and humidity as important factors. As humidity has lately been put into the foreground as a more important factor than temperature, it is of special interest that in such parts of the continents where humidity is very low we find exactly the same development of "respiratory diseases" as on very humid areas. For instance, the incidence of pneumonia epidemics in concentration camps of the U. S. Army from 1917 to 1919 proved that camps with a monthly relative humidity of below 50 per cent. had the same incidence as camps with a relative humidity above 80 per cent.; that camps in Southern California and Texas, with a maximum of sunshine, had the same incidence as those on the Atlantic coast. However, all of the camps in the United States were subject to the incidence of pneumonia epidemics, whenever they happened to be under the influence of certain high air pressure conditions.

Since the appearance of the influenza pandemic of 1889 , we have had a number of references in literature ${ }^{2}$ to the appearance of high pressure periods simultaneously with the outbreak of influenza. A study of such periods became imperative. Anticyclones are formed in the rear of extensive cyclones by the discharge of immense, cold masses of air into lower latitudes. ${ }^{3}$ An area of high pressure results. If the cyclone ahead of this area retards its procession, then a more or less stationary anticyclone is formed. In its center the air is descending by gyration and flowing outward everywhere in its circumference. Its rate of progress is about 41 kilometers per hour in the United States and 25 kilometers in Europe (46 kilometers for the cyclones). Such an anticyclone may remain stationary, however, for from one to four weeks over the entire United States, or the entire area of Europe. Differing from these originally cold anticyclones there appear sometimes others of likewise long duration, which are dynamically warm from the beginning, and which appear to have their origin in the upper circulation of the atmosphere. They are of rather rare occurrence and extend probably into the substratosphere (from 5 to

1. Richter, C. M.: J. A. M. A. 36:188 (Aug. 4) 1894.

2. Richter, C. M.: J. A. M. A. 51:660 (Aug. 22) 1908; 57:1964, (Dec. 16) 1911 ; Anders, H. S. : Philadelphia M. J., Jan. 24, 1903.

3. Hann, J.: Lehrb. der Meteorologie, 1915, p. 624. 


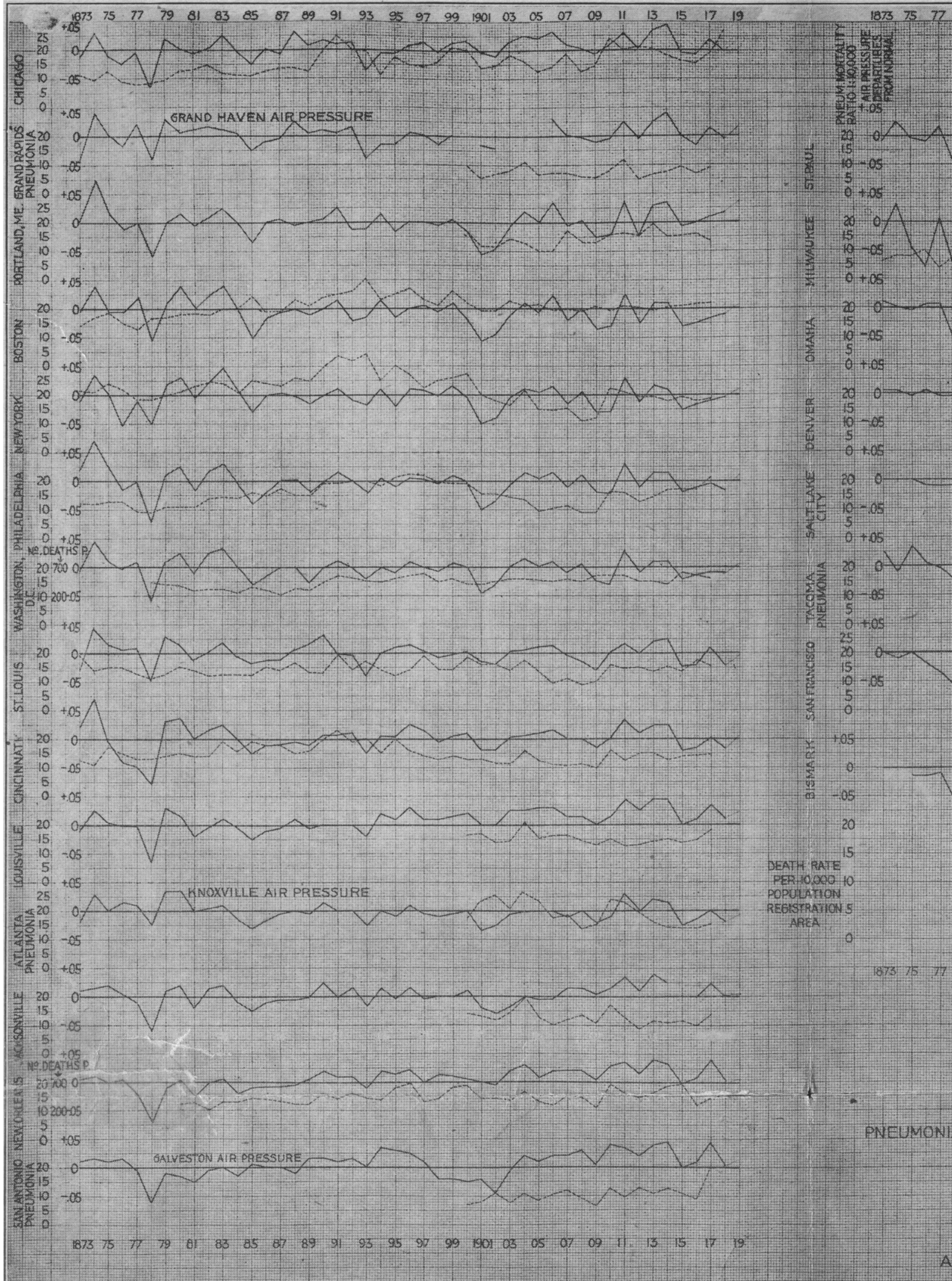

Figure

Downloaded From: http://archinte.jamanetwork.com/ by a La Trobe University User on 12/24/2015 
Continuows line represents air pressure figures, taken at 8 A.M. (Washington D.C.time) ev.ry day, reatuced to Now of Air Weekly lines__ give number of deaths from Pneurnonio, (all forms), and _. - give number of deaths from lnfluen Degthis Pressur

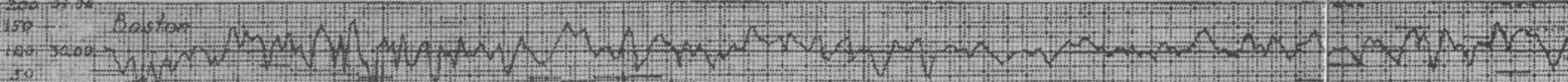
$i_{0} \frac{1}{2900}$ Wenth Ja 120 , Mar

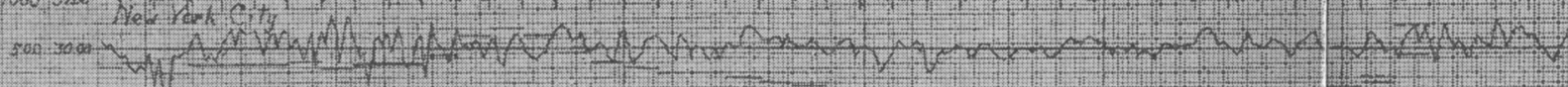

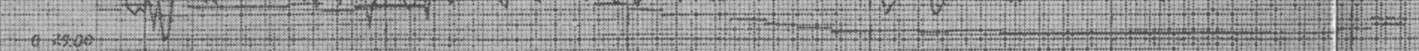

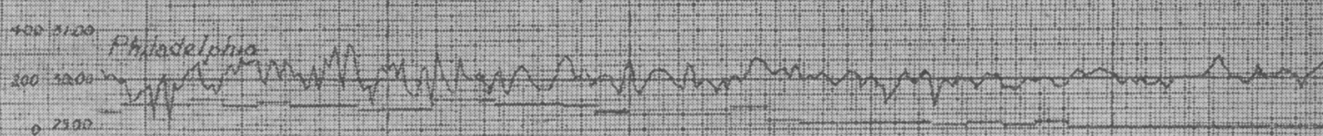

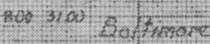

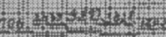

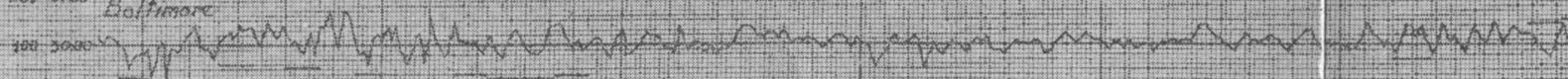
:2900:

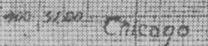

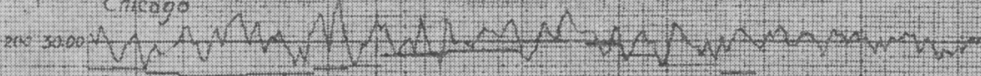

4. 2900

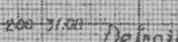

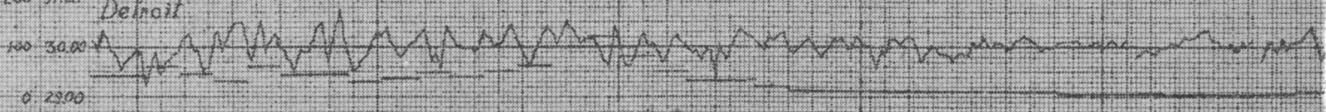

2013100 Cirverano

tetastinting

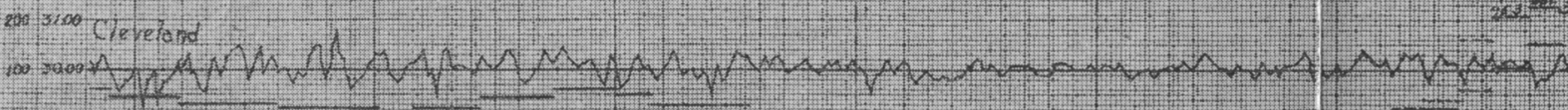

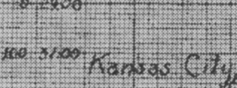

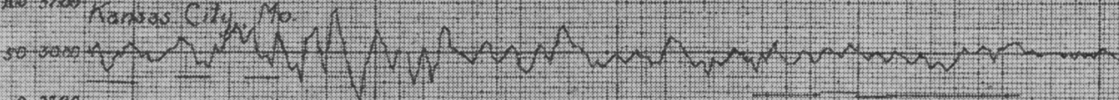

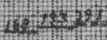

$-10-2400$

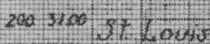

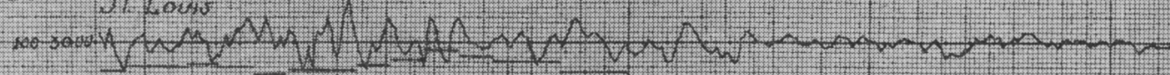

$0+2,202$

100-300 Lowivile

0.2500

too thod Mermiknos

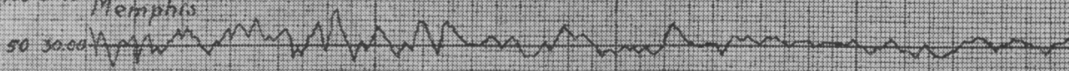

$+2+200$

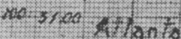

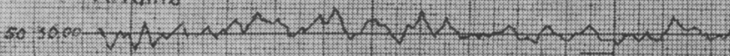

$6-29,65$

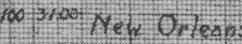

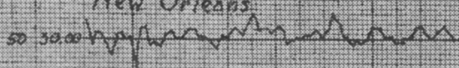

e+2000.2.

20030 . Puitiand, Ore

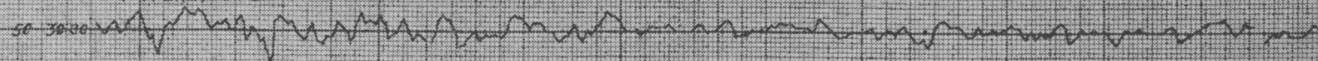

2) 2920

2003100 Sals Francliseo

0 2520

Downloaded From: http://archinte.jamanetwork.com/ by a La Trobe University User on 12/24/2015. 


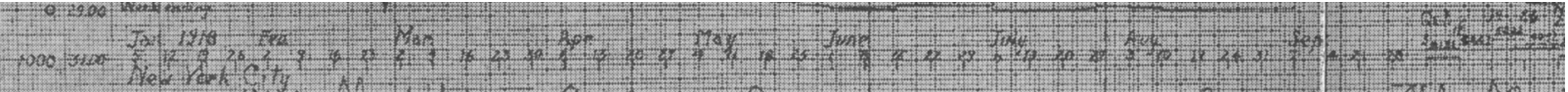

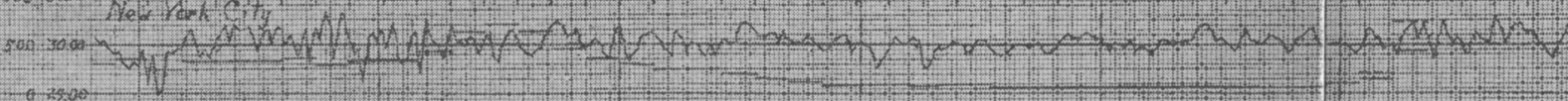

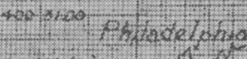

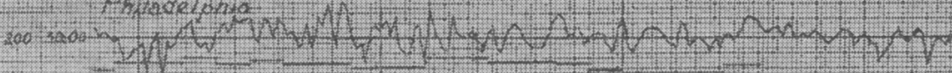

$: 2508$

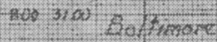

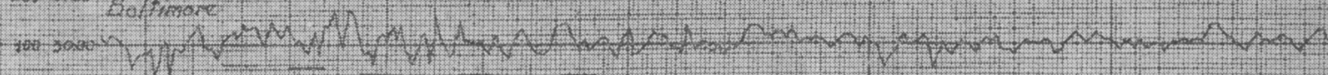

19.

wi. 3rove chicago

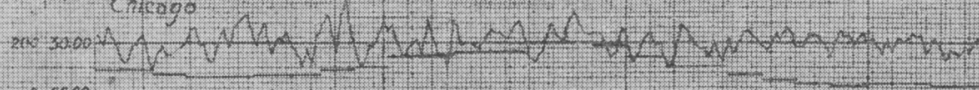

a. 2900.

$200 \rightarrow(202$ Definoti

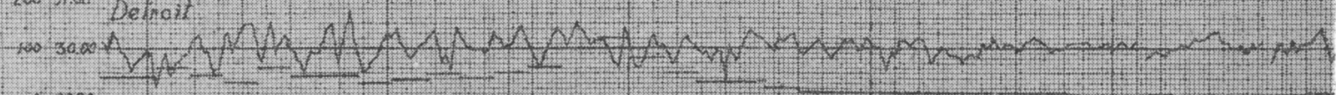

0.200.

2003100 Cleverand

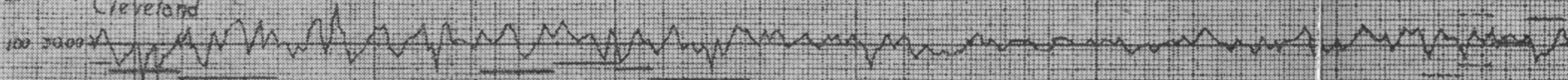
$\div-2+2000$

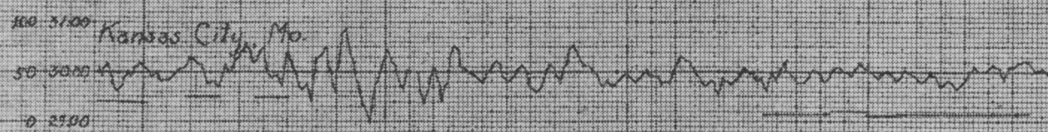

$20+32 \%$

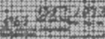

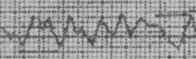
$\cot 20$

$\rightarrow$ ata0

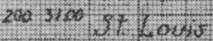

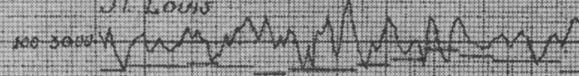

(2) 20000

100-3r0a: Lowisvil?

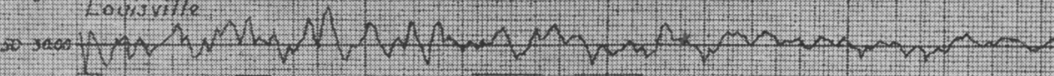

0.2500

too thoo Memphis

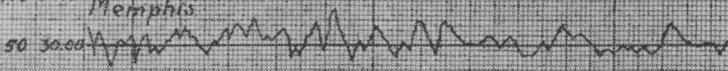

$0-2200$

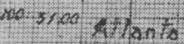

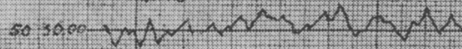

$6 \times 2 \times 0$

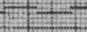

100 3no New Oriesas

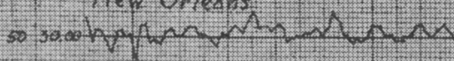

cit-2900:-

200 3iso Panmand. Ore

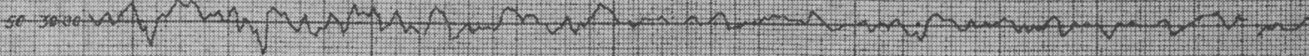

2) 2480

2003 3os Sels franciseo

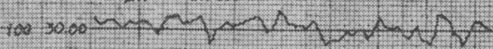

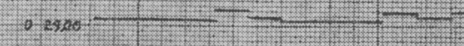

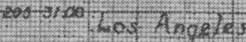

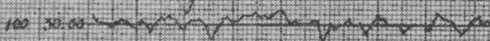

- $2500=-1$

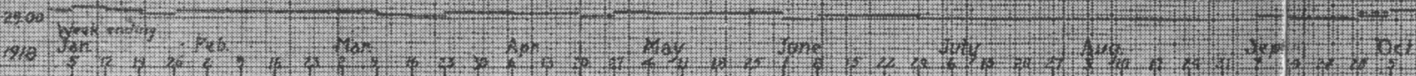

$202 \times 5$

$2 x+2 \times 2$

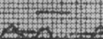


9 kilometers). (The so-called troposphere extends from about 1 to 5 kilometers, and the stratosphere from 9 to 15 or more kilometers).

Our weather conditions do not depend, in reality, on cyclones and anticyclones, but on the great air currents in the substratosphere, which determine the dynamics of the atmosphere. ${ }^{*}$ The entire weather system of the United States, for instance, according to Bigelow, ${ }^{5}$ varies systematically with the variation of sun protuberances and sun spots. An increase of solar activity brings the cyclones into lower latitudes, increases the east drift of the upper air currents, lowers the temperature and increases the air pressure (lowers it at the equator). Koppen ${ }^{6}$ declares that we possess in the eleven year sun-spot period the first directly proven period of weather conditions, even if not parallel to year or day. Naturally, this eleven year period must also be in direct relation to air pressure variations on our continent. Nansen ${ }^{7}$ summarizes thus: In different groups of areas on the earth the meteorologic elements (temperature, rainfall, barometric pressure, etc.) fluctuate, or pulsate, so to speak, in time with one another, while in other groups of areas the fluctuations or pulsations are exactly inverted, and finally some areas show transition stages between the two. The result of all this is a very complicated picture of the meteorologic fluctuations. But by means of appropriate analysis we see that from this complicated and apparently chaotic set of fluctuations there arises a clear picture of the very intimate relation between all these variations, and the variations in the sun's activity. We have seen that even changes of very short duration in the sun's radiation (of heat as well as electricity) are distinctly repeated in our meteorologic conditions. The effects of the solar variations are probably transferred by means of variations produced in the distribution of pressure in our atmosphere. Changes in solar radiation probably first affect the higher layers of our atmosphere and thus create an unrest, which in turn is transmitted to the lower strata near the earth's surface. Such dynamic changes will produce different effects in different regions of the earth. Richter ${ }^{8}$ demonstrated in 1892 this correlation of air pressure and sun-spot periods.

Anticyclones in the United States present four types: ${ }^{9}$

1. Appearing off the Pacific coast, ${ }^{10}$ generally spring and fall; (a) off the coast of Washington and Oregon; (b) off the coast of California.

2. Alberta type (Southwestern Canada) west of the hundredth meridian.

4. Shaw, W. H.: Meteorolog. Ztschr., 1914, p. 67.

5. Bigelow, F. H.: Am. J. Sc., August, 1910.

6. Koppen, W.: Meteorolog. Ztschr., 1914, p. 327.

7. Nansen, F.: J. Washington Acad. Sc., March 4, 1918.

8. Richter, C. M.: Meteorolog. Ztschr., August, 1892.

9. Bowie, E. H., and Weightman, R. H.: Monthly Weather Rev., Supplement 4, 1917.

10. De C. Ward, R.: Ann. Assn. Am. Geographers 4: 1915. 
3. Rocky Mountains-Plateau Region type.

4. Hudson Bay Type, east of the hundredth meridian, region of the Great Lakes.

During the years 1892 to 1912 (inclusive) 1,937 anticyclones and 2,597 cyclones entered the United States.

The following figures give the number of the different anticyclonic types registered during this period:

1. (a) North Pacific, 383.16; (b) South Pacific (California), 192.

2. Alberta, 947.

3. Plateau and Rocky Mountain Regions, 272.

4. Hudson Bay, 143.

Their average speed of progression was 22.7 miles per hour. "These anticyclones generally move east by south, whilst the cyclones move east by north inside the United States. The frequency of anticyclones is greatest in January and least in June. The Alberta Highs not infrequently in the winter months move almost due south to the West Gulf states." 9 As we see, nearly all of the anticyclones appear north of latitude $46^{\circ}$ and west of the hundredth meridian. "Of 81 anticyclones of more than $787 \mathrm{~mm}$. (31"), in America and EuropeAsia (1877-1844) one appeared in October, 8 in November, 34 in December, 29 in January, 4 in February and 5 in March." 3

In Europe four types are recognized. ${ }^{11}$ They are called according to origin:

1. Spanish.

2. Russian-Scandinavian.

3. Central European.

4. Iceland.

The Spanish anticyclone is part of the constant subtropical Atlantic Ocean High, central over the Azores. It extends northerly in summer. sometimes as far as Iceland, but its branches at other times reach Scandinavia on their path across continental Europe. The Azores High in some years may extend easterly to such an extent that one of the great, stable, dynamic Highs is created, locating over the area of Europe for many weeks. The Russian-Scandinavian Highs are typical continental anticyclones, having their nucleus in Siberia, Turkestan or China. Air pressure inside their area may reach $800 \mathrm{~mm}$., while the Spanish type may reach $775 \mathrm{~mm}$. The Iceland Highs probably originate in Greenland, while the Central European Highs appear to be parts of the Russian or Azores Highs.

In an extensive air pressure study, covering the years 1826 to 1885, Hann ${ }^{12}$ demonstrates that periods of very high air pressure

11. Dreis, J.: Meteorolog. Ztschr., Feb. 1, 1915.

12. Hann, J.: Die Vertheilung des Luftdrucks über Mittel- u. Süd Europa, Wien., 1887, p. 110. 
appear only at great intervals. Such a period existed from 1832 to 1836 in Middle Europe, extending from Petersburg to Warsaw, to Hungary, Paris, Basel and Palermo. It was a period of enormously high pressure, not equaled again before 1885. However, Petersburg had very high pressure again in 1839 and 1840. Another fact elucidated by Hann was the existence of a period of distinctly low pressure extending from Warsaw to Palermo from 1851 to 1855 . A long period of high pressure followed from 1856 to 1864 . The years 1874 to 1878 represented a low pressure period. We have no reliable pressure data for the United States before 1873. It appeared to Hann that the maximum pressure progressed from North to South. Hann's table also suggests that the years from 1842 to 1847 were a low pressure period; from 1847 to 1851 being a higher pressure period, and an increasing pressure after 1880 . Hann notes the existence of a continuous rise of pressure during January in all years from 1826 to 1885 , while pressure during April declined. He finds that deviations of pressure from normal have the same intensity and the same general character over the entire area of Europe.

The same fact is exemplified over the area of the United States. It has been made a special study by $F$. H. Bigelow, ${ }^{13}$ who found that:

The secular variations of the barometer from year to year are by no means accidental, but a phenomenon of definite proportions. The years of maximum pressure (over the United States) are 1874-75, 1882-83, 1890, 1896-97 and those of minimum pressure are $1878,1884-85,1893$, with an interval of about eight years each. The years of depression seem to have a wider amplitude than the years of maximum. Between the successive large minima there is usually a large maximum broken in two parts by a minor minimum, as in 1876, 1881, 1889,1895 . These minor depressions are not so persistent throughout the entire United States as the strong minima, and in fact some years there seems to exist a powerful and persistent directive impulse, that really dominates the prevailing pressure. In seeking the causes of this phenomenon, one may suspect purely cosmical causes due to the variable solar output; indeed, these barometric variations do closely follow the variations in the sunspot frequency and the other products of the sun's variable activity. It is evident that we can now correlate the years which have similar secular variations and study them climatologically to see if there are any marked and prevailing features which characterize them.

Bigelow's study embraces the years from 1873 to 1899 . Since then years of minimum pressure have been 1901, 1902, 1909 and 1915 with minor minima in 1905, 1907 and 1912. The maximum pressure years extend continually from 1903 to 1908 and then from 1910 to the beginning of 1915. The last increase begins at the end of 1917 and extends into 1920. The North Dakota Station, Bismarck, seems to act as the key to this long series of high pressure years, showing a rise of pressure from 1878 to 1919 . It is the gate for the Alberta

13. Bigelow, F. H.: Rept. Chief of Weather Bureau 2: 1900, 1901. 
Highs which enter the United States in that region and then sweep over the United States in a southerly and southeasterly direction. Figure 1 shows, in accordance with Bigelow's findings, that certain years of minimum or maximum pressure are very clearly indicated by each station of the chart, most conspicuously for 1878. As Bigelow remarks: "The residuals of that year are persistently minus, 0.05 inch, for each station of the United States: for 1883 they are persistently plus, about 0.02 inch. This means a relative reduction, or increase of air pressure, representing a weight of many million tons of air covering the United States."

If we follow the pneumonia mortality line in Figure 1 we are struck at once by the remarkable fact that the period of low pressure from 1875 to 1879 corresponds with a well marked trough in the mortality curve. The low pressure period from 1884 to 1885 also harmonizes well with a diminished pneumonia mortality. The 1893 Lows are generally followed by the mortality line in the same, or the following year. There is very well marked harmony between the two curves during the "Low" period of 1901-1902, likewise in 1909 and 1915. These are the principal "Low" periods. The United States curve also indicates low mortality during 1901-1902, in 1908-1909 and in 1914. It also gives an intermediate depression in 1905, which is likewise clearly indicated in the air pressure Low.

The principal air pressure maximum period in 1874-1875 harmonizes with the mortality peak in 1875 . The general air pressure rise in 1879 is followed by the general rise of mortality, and both curves extend with this character during the High of 1882-1883. An irregular rise of both curves follows with an intermediate common peak at 1888 . A more definite period of high pressure begins at 1890 - the beginning pandemic-with peaks common also to the pneumonia mortality in $1890,1891,1893,1895,1896,1897,1899$ and 1900, when the Low period appears. The general rise of pressure from 1903 to 1908 exhibits a greater common rise in 1903, still more in 1904, in 1907 and after the Low of 1908-1809 in 1910-1911. A following High period from 1911 to 1915 , has common peaks at all cities, although of an irregular type. The United States curve has well outstanding peaks at 1900, 1904 and 1907. After 1915 we notice a general rise of both curves leading into 1918, when the new pandemic begins at the second half of that year, following a period of unusually low pressure at the beginning of 1918, which is for this reason only not accompanied by a distinctly high pressure line for that year. The United States curve likewise rises clearly since 1915 . It is obvious, that any conclusions that might be formed from this chart, may have to be qualified in regard to the accuracy of the mortality statistics. We may accept the 
POPULATION

NOY. 1 DEC.

JAN.

FEE.

I MAR. I APR

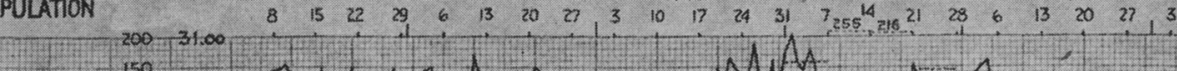

BOSTON

747,923

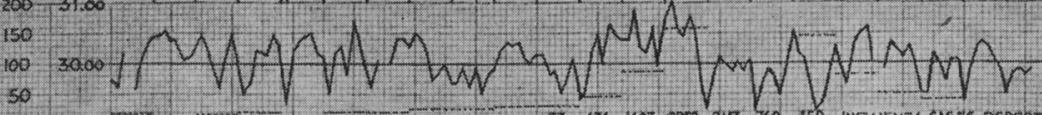

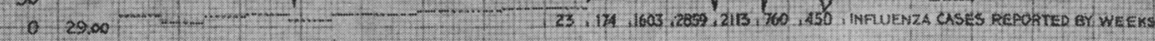

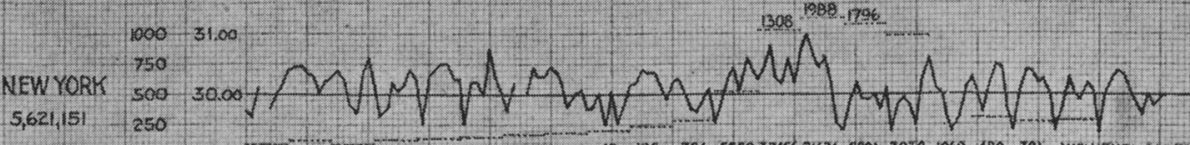

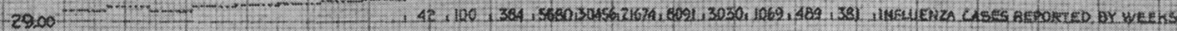
564.628

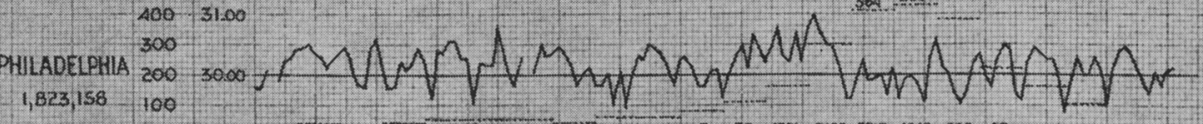

$0-29.00$

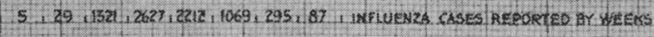

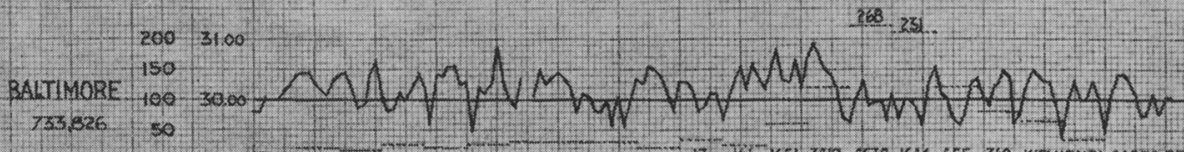

e. 29.00

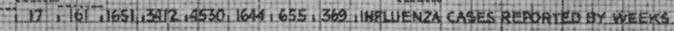

31.00

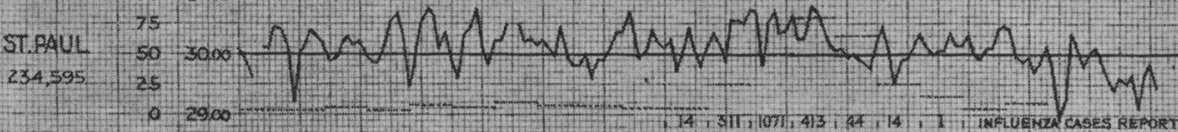

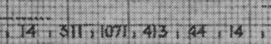

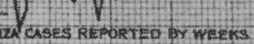

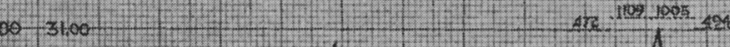

CHICAGO

2,701,202

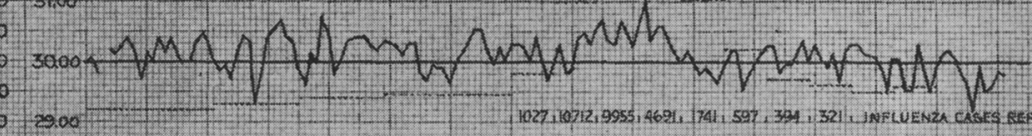
258

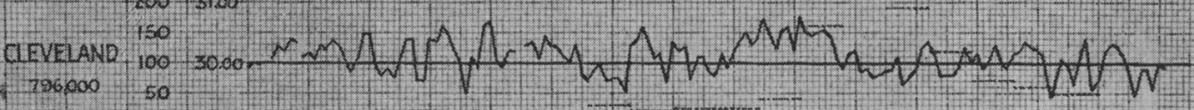

0.2900

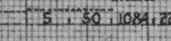

256362

0.2990

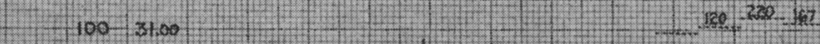

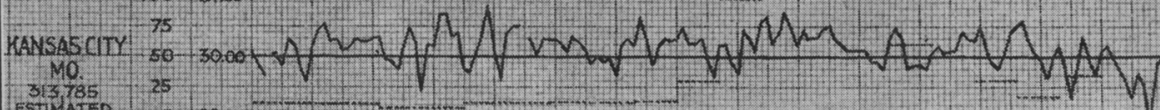

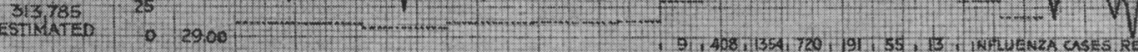

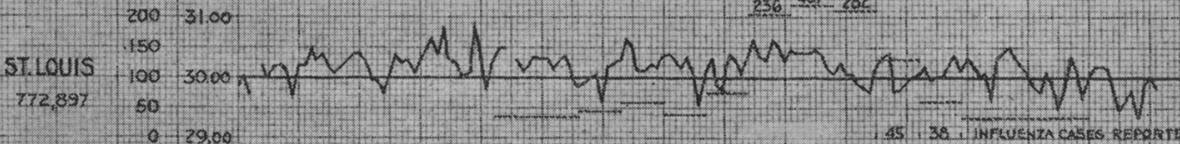

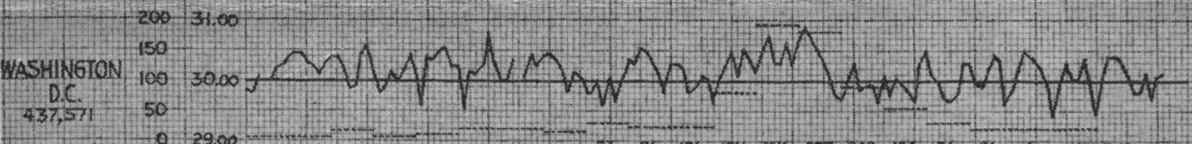

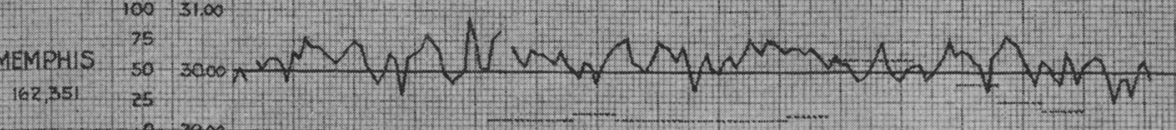

$100 \quad 31.00$

Downloaded From: http://archinte.jamanetwork.com/ by a La Trobe University User on 12/24/2015 $\mathrm{N}$ NA 
air pressure statistics as being practically free from great errors, but not those giving pneumonia mortality.

The census figures, for instance, differ in some cities materially from those of their health boards. Perhaps a reduction in the mortality line since 1900 is to be attributed somewhat to the policy of the "Census" to eliminate many cases of pneumonia, that had been classified under "primary cause of death." Great errors may also occur by the estimation of population. However, there remains a coincidence of gigantic departures of air pressure and gigantic pandemics. Our largest cities exhibit the same general tendency of rise and fall of both curves during definite periods of many years, and this by means of an annual air pressure curve that necessarily cannot elucidate the relation of cause and effect as a daily air pressure curve. Mean figures may be extremely misleading in certain years. St. Louis and San Francisco have the same mean annual temperature. The extremes of summer and winter in the former city permit of wrong conclusions in this comparison. Similarly low pressure periods at the beginning of 1918 and developing again toward the $-\mathrm{d}$ of the year reduce the average pressure of the year sufficiently to conceal the unusual anticyclonic activity occurring between the two periods of low pressure. However, the general agreement in rise and fall of the two curves may at once suggest certain possibilities, as a rise of mortality following only certain types of anticyclones. For instance, so-called wandering anticyclones may constitute a positive departure of pressure in some years with a physiologic or pathologic influence on animal life different from that caused by the dynamic anticyclones as they appeared during the different pandemics. Only a careful pertusal of daily air pressure conditions as presented on the other charts will give a proper understanding of possible cause and effect. The San Francisco charts are especially illuminating in that respect.

I may add here, that as Hann's ${ }^{12}$ figures proved for the period from 1826 to 1885 , likewise the evidence given by Richter ${ }^{1}$ and Anders ${ }^{2}$ corroborates the simultaneous appearance of unusually high barometric pressure during the influenza period from 1889 to 1897 . The cities in Europe, generally, show the same years of minimum pressure, 1878, 1885,'1893, 1901-1902, and the same years of maximum as the United States, 1874-1875, 1882, 1889-1890, 1897-1898, 1905 1908. It should be noted here, that Lockyear ${ }^{14}$ proved that in certain years the southern hemisphere is affected generally in the same months by high pressure conditions as is the northern.

Figure 2 shows that the different cities (Pacific Coast cities generally included) are exhibiting the same type of Low or High at the

14. Lockyer, N., and Lockyer, W. T. S.: Proc. Roy. Soc. Lond., October, 1902. 
same time-with a difference of, perhaps, only one or a few days. This uniformity is remarkable, and is equal to the uniformity found by Hann for Middle Europe. However, the extent of increase and decrease of air pressure in certain Lows and Highs seems extreme in the more northern cities, compared to those in lower latitudes. This is well explained by the record of the variability of the mean monthly pressure in different latitudes, following Hann. ${ }^{3}$

Table 1.-Mean Monthly Pressures in Different Latitudes

\begin{tabular}{llcccccccc}
\hline Iatitude, degrees N. ............ & 60 & 56 & 52 & 48 & 46 & 43 & 38 & 32 & 20 \\
Mean variability, $\mathrm{mm} . \ldots \ldots \ldots \ldots$ & 3.06 & 2.92 & 2.58 & 2.34 & 1.95 & 1.80 & 1.48 & 1.00 & 0.40 \\
\hline
\end{tabular}

The air pressure conditions existing before and during the last influenza pandemics in the United States are outlined as follows in the different Monthly Weather Reviews (U. S. Weather Bureau) :

August, 1918. - "Pressure was high on several occasions on the West Coast, but there was no progressive movement (two stationary Highs near the 11th and 22nd of August). On the fifteenth rising pressure over northern Manitoba indicated the formation of an independent High." Pressure increased over Michigan, and on the nineteenth "this High was probably the controlling factor of the weather over the northern and central portions of the American continent." There was "a failure of the stationary areas of high pressure to progress eastward."

During September "there was entire absence of strong cyclonic action throughout the United States proper" and "the average barometric pressure was above normal through the whole country."

During October "the Highs were the dominating weather control of the month--there was more or less merging of North Pacific Highs with Highs which first appeared over the Canadian Northwest. The North Atlantic High was of greater intensity than usual."

During Norember "the Lows during the first half of the month, as in October, were decidedly lacking in intensity-the central portions of the country from the Atlantic to the Pacific were mostly under the influence of high pressure-after the fifteenth there was a marked increase in the intensity of the Lows-practically throughout the month pressure was above the normal off the California coast." Some of the Highs during this month disappeared rapidly. However, on the nineteenth "a marked rise in pressure had overspread Alberta. This rise advanced southward to Montana and to the West Gulf States and a branch of it reached Illinois and Mississippi on the twenty-third." "The Azores High was considerably greater in intensity than usual, and about 1,000 miles northeast of its usual position." 


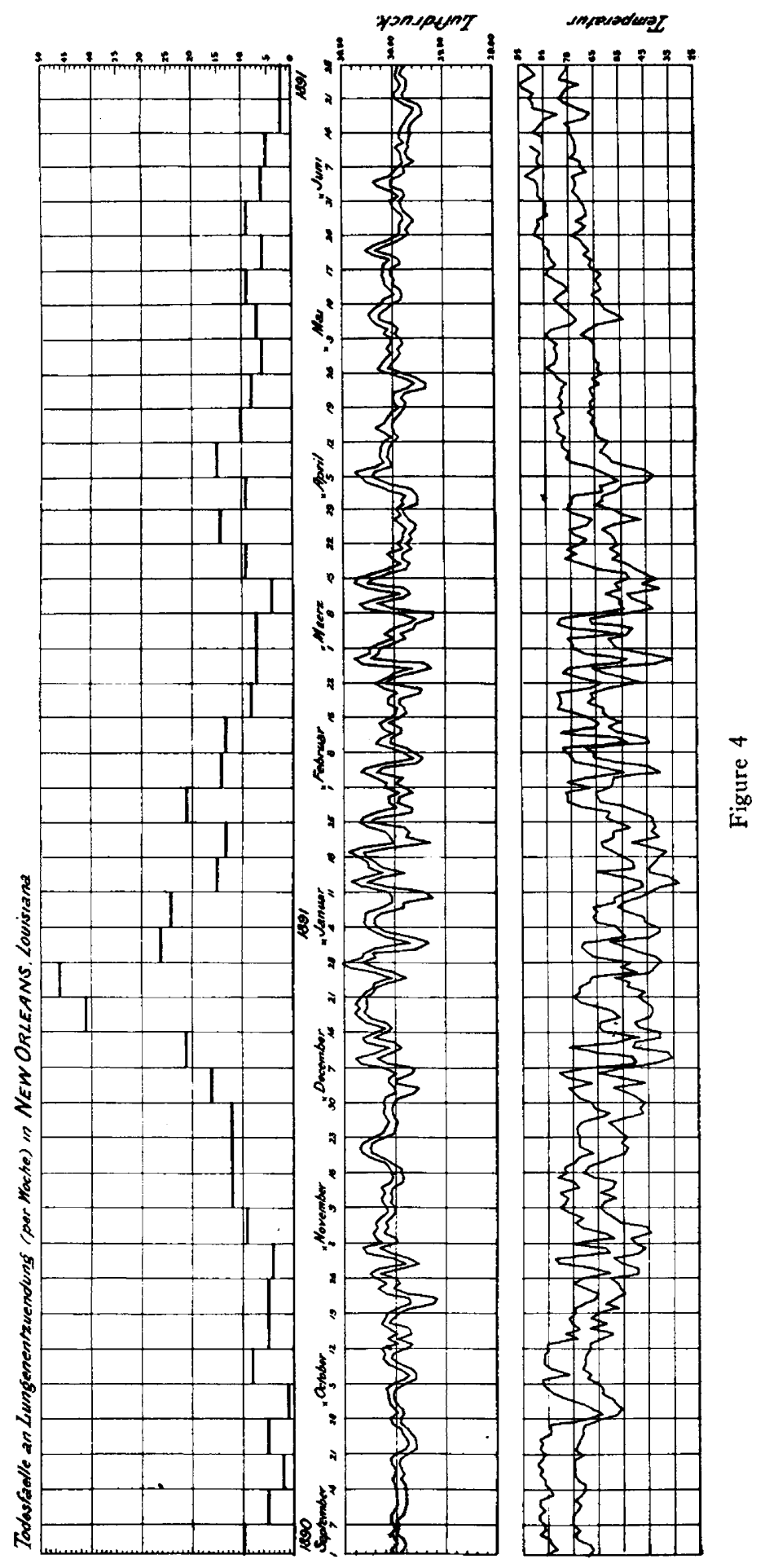


During December "the average sea level pressure was below the normal in the great central valleys and over the far Southwest, but elsewhere it was generally above normal." The Azores High was still similar to the November type.

During January, 1919, "the uniformly low pressure which had prevailed at Honolulu since December, 1917, gradually merged into a type of moderately high pressure and there was still further increase during January, 1919.” In the United States “a general increase in pressure over middle latitudes - an almost constantly maintained High over the Plateau region-as a result the average for the month was well above the normal over the entire region from the Rocky Mountains westward, and from the Central plains eastward."

During February "pressure in the Northern Hemispheres, as in January, was high over the middle latitude of the continents and the Atlantic Ocean, 30.60 inches over parts of Siberia-a ridge of higher pressure apparently connects the continental Highs of northeastern Asia and the North American continent by way of Alaska and the Bering Sea." For the United States proper we learn that "the average pressure was below normal in practically all portions of the United States."

During March "there is a rather pronounced fall over the great continental Highs, amounting to 0.20 inch in Siberia and about half that much on the North American continent."

As the pandemic (Fig. 2) began about Sept. 1, 1918, in Massachusetts, ${ }^{15}$ we find that this beginning was preceded by a development of stationary high pressure affecting the West Coast as well as the northeast of the United States during the second half of August. ${ }^{16}$ We notice on the chart the entire absence during August and September of strong cyclonic action. The pandemic increased in severity until about October 12 (Boston); October 20 to 26 (New York, Chicago and San Francisco). The pressure likewise increased continuously and during October "the Highs were the dominating weather control." However, after October 5 Boston was experiencing development of Lows, while New York and the other cities had this deficiency in pressure one or two weeks later. The more or less rapid decline of the pandemic runs parallel to this development of low pressure on every city on the chart. About November 20, a second increase of

15. Pub. Health Rep., Sept. 27, 1918, p. 1626.

16. Sept. 17, 1918, report was made of the continued occurrence of a considerable number of cases of influenza at Boston and vicinity, where upward of 200 cases occurred on the day of the report, with a total of about 2,500 cases known to have developed during the outbreak. Sept. 17, 1918, the extensive prevalence of an influenza-like disease was reported at Camp Lee, Va. ${ }^{17}$

17. Pub. Health Rep., Sept. 20, 1918, p. 1604. 
pressure begins, and it is followed by a second development of the pandemic in every city relative to this development. The morbidity apparently has its peak about December 20 and the mortality about two or three weeks later. This second increase of air pressure has its peak about December 19, somewhat later in Louisville and the
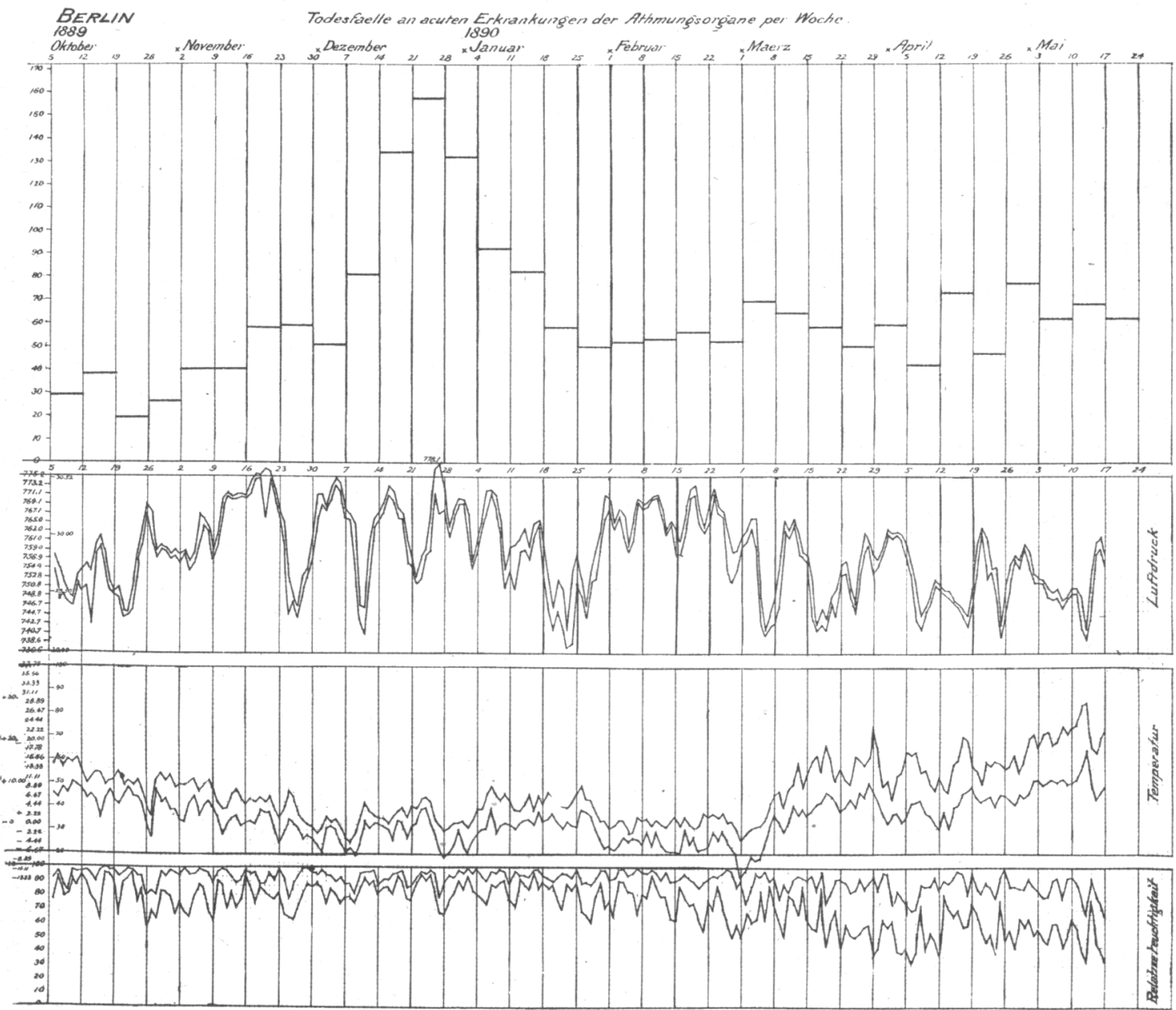

Figure 5

Pacific Coast. Following this, we find a marked intensity of low pressure continuing to February 14 and a few days earlier on the Pacific Coast. A new increase of air pressure during the middle of March is short lived on the Atlantic Coast, but of some duration at Chicago, Cleveland, Kansas City to Louisville, and we find in that area a moderate recrudescence of the epidemic. 
No unusual features in weather or mortality develop until toward the end of 1919. In November, 1919, mean pressure in the Northern Hemisphere is characterized by a great continental High over northern Asia, relatively high pressure in a belt which engirdles the globe about 35 degrees north latitude." The weather in North America is largely controlled by the depth and persistence of the low pressure in the North Pacific-also by cyclones which form on the southern border of the semi-permanent High in middle latitudes-but cyclonic systems of pronounced character were notably absent. The average pressure showed the highest area extending as usual from the South Atlantic States northwestward to the northeast Rocky Mountains and Plateau regions with the maximum over Wyoming. Pressure was lowest over the Southwest."

During December, "the pressure at the Azores was considerably higher than usual." In the United states "the weather was distinctly under anticyclonic control, but during the third decade of the month lower pressure was the rule in practically all parts of the country. The excess of average pressure of December was least over the South Atlantic and East Gulf States and along the central and south Pacific Coast."

During January, 1920, "pressure over the United States alternated between low and high during the first and second decades, except in the Rocky Mountain Region, where it was high, while during the last decade it was almost continuously above normal throughout the entire country. Fifteen anticyclones entered the United States against nine, the average number for January-ten of them the Alberta type and four Plateau and Rocky Mountain region type. The most important features were the persistence of high pressure from the seventh to the nineteenth over the northern and central plateau regions-high pressure prevailed over the northern districts rising above 31 inches in eastern Montana. This high area moved along the northern border, but its influence was felt far to the southward. At the end of the month this high pressure area covered the northeastern States and some of the highest barometer readings ever observed in that region were reported. The average pressures for January were above normal in all portions of the United States and likewise in Canada as far north as observations disclose."

February opened "with a pronounced fall of pressure near the Aleutian Islands, where since January 10 it had been abnormally high. The extremely high area of the end of January moved rapidly into the Atlantic and was quickly followed by another that prevailed for several days from the Great Lakes eastward. During the same period pressure was generally high over the far West and low in the Southeast, where 


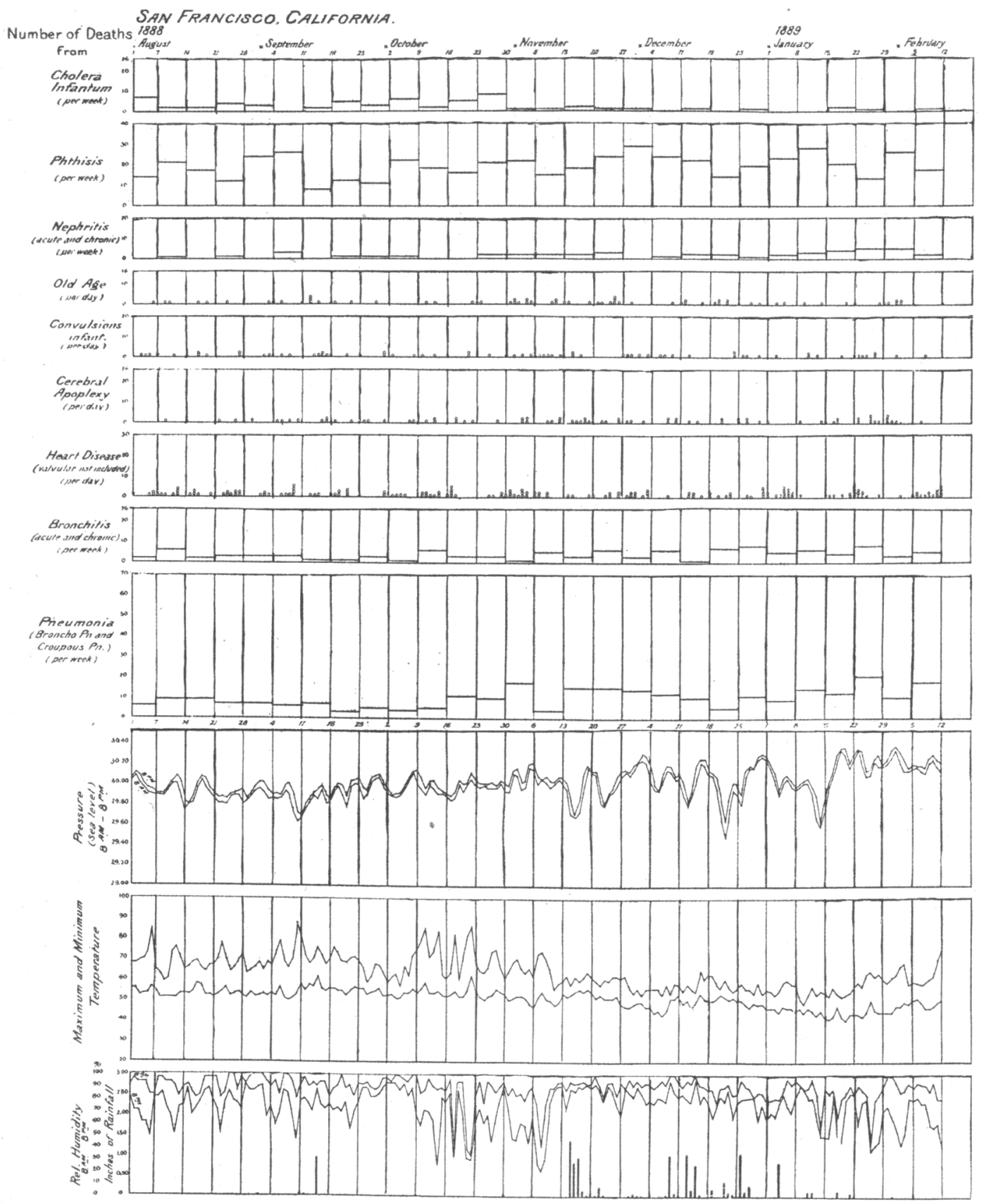

Figure 6 
a Low moved northward from Florida up to New England. The average pressure of February was above normal over practically all the portions of the United States and Canada from the Mississippi and the Great Lakes westward to the Pacific, the departure increasing in the far northwestern districts, where at points it was the highest on record. In the eastern districts of the United States, as well as of Canada, it averaged considerably less than normal, particularly along the middle Atlantic Coast." Twenty cyclones entered the United States as against 11.9 , the normal number, and ten anticyclones as against 7.8 normal.

March "was characterized by a remarkable series of cyclones that moved across the United States. Abnormally low pressures prevailed in every instance. An extensive and marked high pressure wave followed the storm of March 1 to 7 , principally in the Southeastern States, but there were no other Highs of consequence-the averages of the month were below normal over practically all portions of the United States west of the Mississippi, north of the Ohio and over Canada." Eighteen cyclones entered against 11.8 normal, and ten anticyclones against 8.5 normal.

A general tendency to increase of pressure over the North American continent and a relative absence of cyclonic activity again characterize the weather of two months preceding the January, 1920 pandemic (Fig. 3 ). But instead of the gradual increase of high pressure we find, near the end of 1919, a more explosive increase of high pressure and during January, 1920, a gigantic High controlling the weather of the continent during the four or five weeks of the pandemic. The pressure condition during November and December, 1919, apparently helped to prepare the way, as we find a distinct gradual increase in the pneumonia mortality, beginning after the middle of November, notably in New York and Chicago. At the beginning of December, this influence is shared by almost all the cities on the chart, while the actual beginning of the pandemic, as indicated by the morbidity figures reported by weeks, may be traced directly to the relative development of very high pressure beginning about January 3 in the different cities.

A careful study of the individual cases in regard to the relative value of intensity of pressure and the partial interference by minor cyclonic action easily emphasizes the parallelism of the pandemic and the high pressure condition, which latter comes to an end about February 4 by a most intense cyclonic action. From the first week in January we note a very uniform pressure type for the cities on the Atlantic Coast and for the area from St. Paul and Denver to Chicago, Kansas City, Memphis and Atlanta. New Orleans participates in a general way, but the Pacific Coast again resembles the Eastern type. 

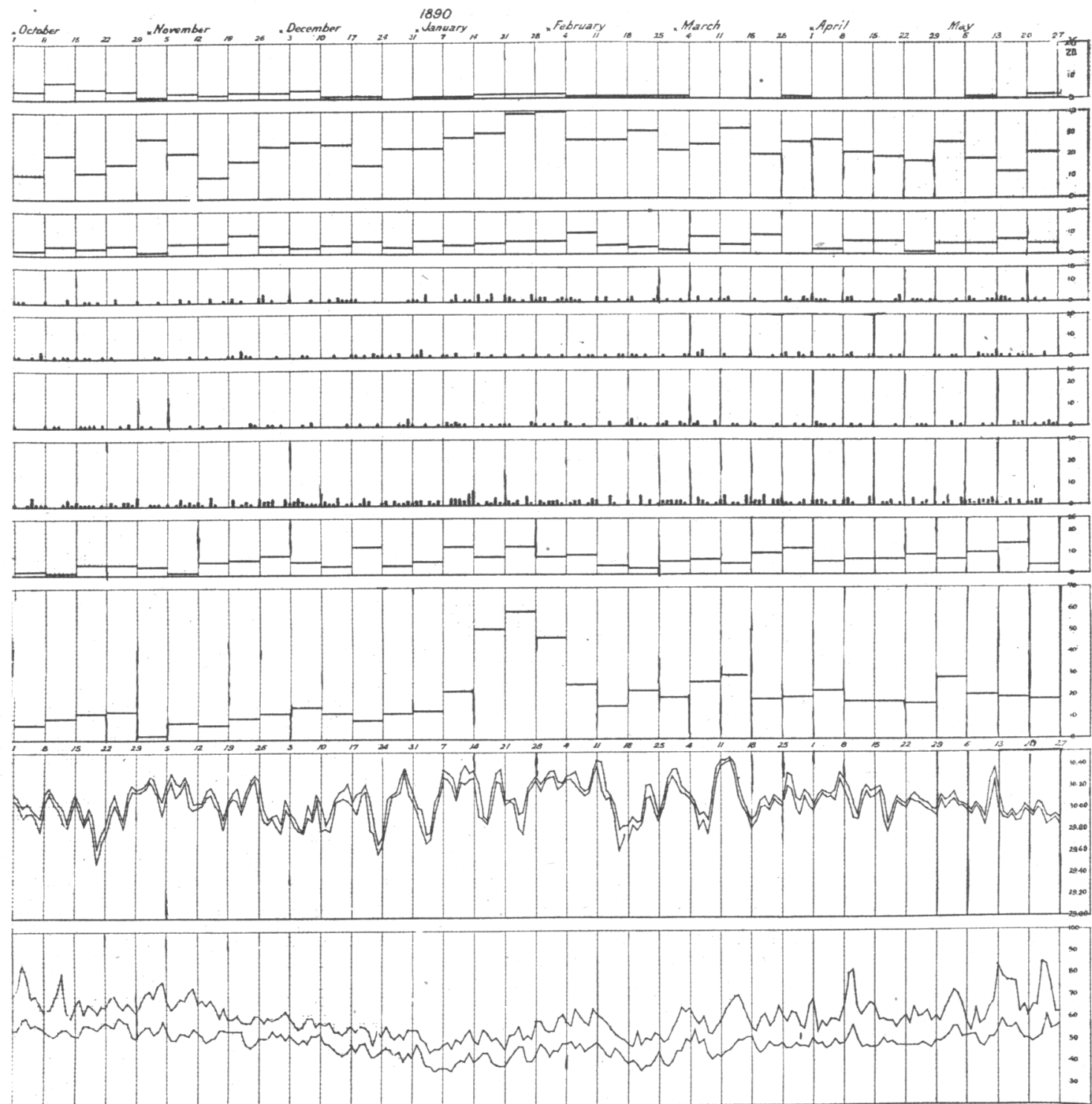

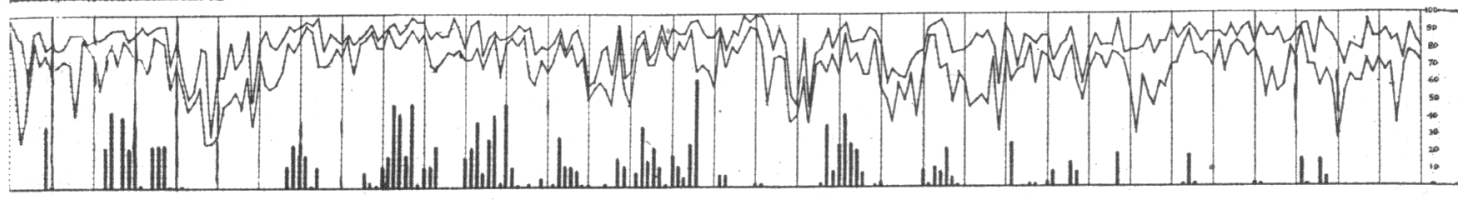

Figure 7 
which antedates the Pacific type by from one to two weeks. The Chicago type is at least one day ahead of the Atlantic Coast type and here, if we consider the report of influenza cases, is the first firm hold on the population-the other cities following in direct proportion to the development of the High over their area. The largest number of cases were reported for two weeks previous to the sudden collapse of the High, which occurred after February 4. Only Baltimore and Atlanta have a higher figure of cases for the week ending February 19, and San Francisco and Los Angeles likewise. Local difference in air pressure runs parallel to this difference. It is clear that the mortality line would lag behind from one to three weeks and longer.

Morbidity statistics relative to influenza are still far from ideal, but were, during the January, 1920 pandemic, probably more accurate than ever before. They were not sufficiently available before, except for a few states and cities. ${ }^{18}$ Of these we find the highest number of cases reported :

TABLE 2.-Influenza Morbidity Statistics

\begin{tabular}{|c|c|c|}
\hline & For Week Ending & Cases \\
\hline 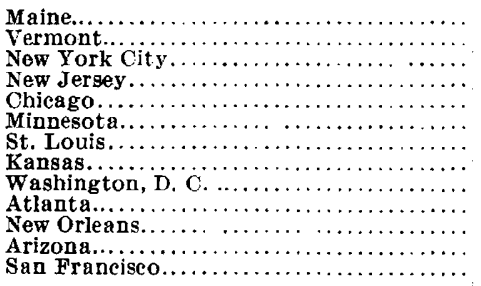 & $\begin{array}{l}\text { Oct. } 26,1918 \\
\text { Oct. } 21,1918 \\
\text { Oct. } 19,1918 \\
\text { Oct. } 19,1918 \\
\text { Oct. } 19,1918 \\
\text { Oct. } 26,1918 \\
\text { Oct. } 19,1918 \\
\text { Oct. } 19.1918 \\
\text { Oct. } 12,1918 \\
\text { Oct. } 19,1918 \\
\text { Oct. } 19,1918 \\
\text { Oct. } 19,1918 \\
\text { Oct. } 26,1918\end{array}$ & $\begin{array}{r}6,754 \\
6.949 \\
32,884 \\
77,215 \\
12,183 \\
26,853 \\
4,043 \\
14,892 \\
9,708 \\
1,594 \\
17,070 \\
3,530 \\
8,682\end{array}$ \\
\hline
\end{tabular}

The report giving these figures states that "they are not exact or even more than approximately accurate." Only in Baltimore ${ }^{19}$ has the attempt been made to trace cases of influenza back to August 1, 1918, but none are tabulated for August, while from September 1 an ever increasing number of cases is given until middle of October. A rather rapid decline begins about October 21. The outstanding fact is again the collapse of the epidemic following closely the cyclonic action, which begins with the second decade of October, 1918.

Even during the last pandemic mortality and morbidity statistics have been rather crude, but sufficiently complete in some cities to compare the time factor of the outbreak, peak and decline of the pandemic to the numerical values of atmospheric conditions, as measured by air pressure figures. The two factors easily explain the variation among cities in their different epidemiologic characters. Especially the Jan-

18. Pub. Health Health Rep., Nov. 8, 1918, p. 1914.

19. Pub. Health Rep., March 14, 1919. 

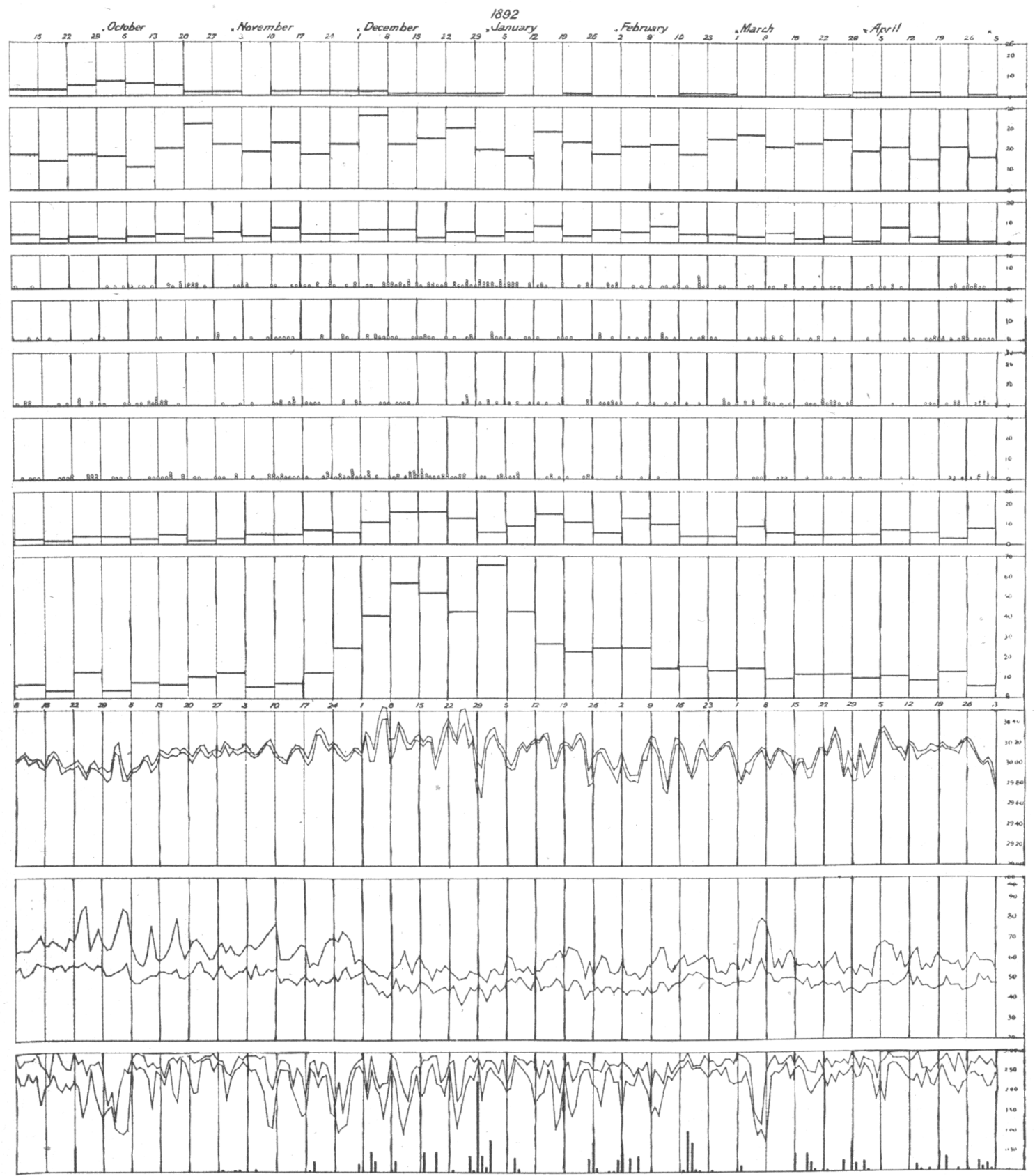

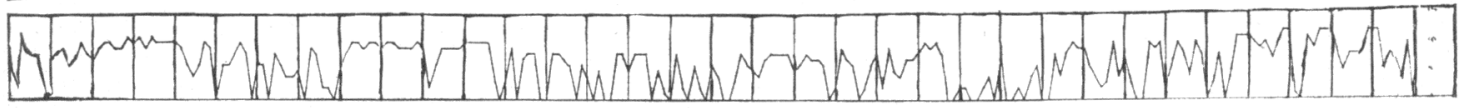

Figure 8 
uary, 1920, pandemic proves the indisputable truth of their interdependence. Looking back to the 1890 pandemic we recognize in the examples of Berlin, New Orleans and San Francisco, the same decisive characteristics. They exhibit the same increase of air pressure towatd the beginning, the same extreme High during the peak and the same collapse of the pandemic by the start of intense cyclonic action.

Comparing the San Francisco, New Orleans and Berlin charts for the pandemic 1889-1891, we find the following (Figs. 1, 2, 3, 4, 5):

TABlE 3.-Influenza Morbidity. Air Pressure and Cyclonic Action

\begin{tabular}{|c|c|c|c|}
\hline & $\begin{array}{l}\text { Mortality Peak } \\
\text { or Increase }\end{array}$ & $\begin{array}{c}\text { Air Pressure Peak } \\
\text { or Increase }\end{array}$ & $\begin{array}{l}\text { Cyclonic } \\
\text { Action }\end{array}$ \\
\hline Berlin................ & Dec. $21-28,1889$ & Dec. 9-23. 1889 & Dec. $23-30$ \\
\hline Second wave... & $\begin{array}{c}\text { Dec. } 30,1889 \text { to Jan. } 1 \text { í, } \\
1890 \text { and Feb. } 1 \text { to } \\
\text { March } 8,1890\end{array}$ & $\begin{array}{l}\text { Dee. } 25 \text { to Jan. } 17 \text { and } \\
\text { Feb. } 1-22,1890\end{array}$ & $\begin{array}{l}\text { Jan. } 18-31 \text { and Feb. } 23 \\
\text { and following }\end{array}$ \\
\hline San Francisco.. & Jan. 21-28, 1890 & Jan. $7-21,1890$ & Jan. $21-28$ \\
\hline Second wave... & Feb. 18 to March 18 & Jan. 28 to Feb. 11,1890 & Feb. 11 to March 11 \\
\hline New Orleans.... & Dec. $14-28,1890$ & Nov. 1 to Dec. 28,1894 & Dee. 29 to Jan. 11,1891 \\
\hline Second wave.......... & Jan. 28 to Feb. 1,1891 & Jan. 4-20, 1891 & Jan. 20 and following \\
\hline San Franciseo. . & Dec. 8 to Jan. 5, 1891 & Nov. 20 to Dec. 6,1890 & Dec. 27 and following \\
\hline
\end{tabular}

If we review the air pressure conditions during the recent pandemics, we recognize the identical anticyclonic action that characterizes the 1889 to 1891 pandemics. The first advent of those pandemics is heralded by a protracted continuous anticyclonic development, not interrupted by any cyclonic action. The first big pressure wave is followed then, as now, by one or two succeeding Highs, lasting again for weeks at a time. The intervals between them have cyclonic action. The mortality line has the same relation to the pressure types in both series of pandemics. Somewhat different is the pressure type at the time of the 1890-1891 pandemic at San Francisco, and of the January, 1920 pandemic in the United States. Both these types are not followed by succeeding waves. Both types have a more abrupt rise and fall of mortality and air pressure lines. The 1890 and the recent pandemic occurred during an advent of high pressure over our hemisphere, that in each case had been extending over some years previous to the outbreak of influenza and that apparently came to its highest and more specific development during or just ahead of the pandemic. I have charts that give the weekly mortality and daily air pressure for San Francisco from 1888 to 1904 (16 years) and for Berlin from 1887 to 1911 (24 years). The explosive appearance of influenza and pneumonia mortality are there confined exclusively to such periods as are narked by the advent of unusual anticyclonic action. 
In addition to these facts we may consider the time relation of influenza pandemics and high pressure periods for middle Europe (since 1827) and for the United States (since 1873).

Of course, this secular coincidence of the pandemics and the high pressure periods does not enlighten us about the cause of an influenza pandemic or of an increase of pneumonia mortality, but it opens a window into the strange character of influenza. It certainly points to a distinct interdependence of the two, and points to the anticyclone as the decisive factor.

TABLE 4.-Time Relation of Influenza Pandemics and High Pressure Periods

\begin{tabular}{|c|c|}
\hline Air Pressure Periods & Influenza and Pneumonia Pandemies \\
\hline $\begin{array}{l}\text { High } 1831 \text { to } 1841 \text {, including "highest air } \\
\text { pressure period (1832 to 1836) not equaled } \\
\text { during the period } 1826 \text { to } 1885 . " 13 \\
\text { Low } 1842 \text { to } 1847 \text {, beginning in some coun- } \\
\text { tries } 1838 \text {. } \\
\text { High } 1847 \text { to } 1851 \\
\text { Low } 1851 \text { to } 1853 \text {, distinctly low from } \\
\text { Warsaw to Palermo } \\
\text { High } 1856 \text { to } 1864 \text {. } \\
\text { Low } 1874 \text { to } 1878 \text {, distinctly low .pressture } \\
\text { over United States ind Europe. } \\
\text { High and increasing } 1881 \text { to } 1900 \text { over the } \\
\text { Lnited States and Furope and continu- } \\
\text { ing. } \\
\text { Low } 1898 \text { to } 1902 \text {. } \\
\text { High } 1902 \text { to } 1920 \text {, definite period of in- } \\
\text { creasing high pressure. }\end{array}$ & 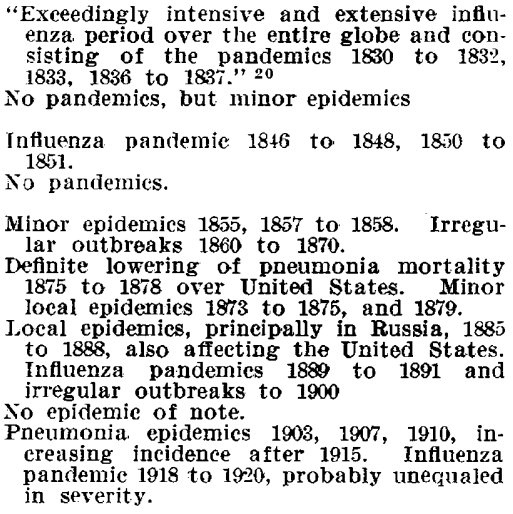 \\
\hline
\end{tabular}

The very source of the pandemics is found to be in that part of inner Asia or North America on the northern hemisphere where the centers of highest pressure are located on those parts of the continents. The air, carried by such dynamic anticyclones during their extreme development all over the two continents, is distributed with an anticyclonic velocity equal to that of our railroad trains.

The direction in which the air is carried out of the center of an anticyclone, varies, of course, with the location of the center. Suppose the center be at St. Louis, the air flowing out of the center would be carried by northwesterly winds toward Boston, by northerly winds to the middle Atlantic Coast, by northeasterly winds to the Gulf States, by easterly winds toward New Orleans and Texas, by southeasterly winds toward the Pacific Coast. Hann" summarizes thus: "The air circulation in the dynamic barometer maxima of the United 1912.

20. Leichtenstern, O., and Sticker, G.: Influenza, Ed. 2, Wien. and Leipzig, 
States, therefore, consists (1) of a true downward directed gyration near its center and extending about 500 kilometers outward; (2) in its outer circumference the motion everywhere has an outward direction and represents a forced rotating motion similar to a whirl in a stream." It is also stated by him that the barometer minima do not supply the air that enters the maxima above, as they do not reach to such height. The distance of the center of a dynamic anticyclone from that of a cyclone is generally about 2,000 miles in the United States and often more than that in Europe.

It is clear that only a most careful study of the daily weather maps will explain the actual air conditions in a certain district relative to a dominating influence of a High or Low. Furthermore, only such study will inform us whether a High is of the quickly wandering type or of a stationary dynamic character. Only continuous crowding of air over vast parts of the country, for instance, over the entire United States or over Europe, lasting quite a number of weeks, seems to carry the character that increases pneumonia mortality severely and paves the way for or starts a pandemic. As we have no special sense for electricity, nor for air pressure and its variations, we do not become aware of the differences that exist in the air we breathe during changes in those factors. It seems reasonable to consider the possibilty that during the development of such unusual high pressure conditions, the physicochemical nature of the atmosphere that reaches our lungs has been altered in such a way that it may affect us more or less disastrously. Or, we may be induced to suppose that such air has become the carrier of a virus. The air of an anticyclone has been descending from a 10 to 20 kilometers height and naturally has been differently qualified during different solar activity. As soon as low pressure sets in, which carries the anticyclonic air away from us, influenza and pneumonia decline. It is difficult to harmonize this behavior with a bacteriologic origin of those diseases.

If we assume that the atmosphere acts as carrier of the cause of influenza, we are facing similar difficulties, as when we were forced by certain facts to assume that the water acted as carrier of the cause of typhoid fever and cholera. Now we know that infection of water is the most common source of widespread epidemics, originating in the contamination of a well or spring. Such epidemics are often as "explosive" as the pandemics. But how can infection be carried by the air, except with dust? But why do we insist on a virus, on an infection as the cause? Certainly only for sake of an analogy, that at best can be only a partial similarity. There is, however, a greater similarity between the march of the pandemic and that of the dynamic anticyclone. Both reach ships on the ocean, islands, distant camps that had 
been as far removed from the pale of civilization as the North Pole. Is there, perhaps, a special physicochemical quality imparted to the air we breathe during a pandemic, imparted, for instance, by the radiant energy of the sun, by radioactivity, by ozonization? Lenard and Ramsatter ${ }^{21}$ define the principal effect of the solar output on the atmosphere: First, the development of ozone "welche ziemlich tief herabreicht, weil sie schon durch schwach absorbierbare Strahlen bewirkt wird." Second, the continuous creation of fognuclei in the upper atmosphere. ("Amonnitrat und Nitrit aus dem lichterzeugten Ozon und dem Ammoniak der Luft, wahrscheinlich auch Wasserstoffsuperoxyd aus Wasserdampf.") Third, continuous creation of carriers of electricity.

W. J. Humphreys ${ }^{22}$ says: "One would expect to find an appreciable amount of ozone in the upper atmosphere, but, owing to its unstable nature and its great power of oxidation, very little near the earth. Only traces of ozone are found in the lower portions of the air and when there is much moisture and the temperature is high the amount is vanishingly small. On the other hand, Augstrom, by examining the absorption bands in the solar spectrum, has detected the presence of a very considerable amount of ozone, which must be in the upper air." "Ozone is produced by the action of ultraviolet radiation on cold dry oxygen; its amount, therefore, must vary with the amount of ultraviolet radiation sent out by the sun and this is a variable quantity." "Besides ozone is abundantly produced by the action of silent electric discharges ; therefore, the amount of ozone in the atmosphere, since it results from the action both of auroral discharges and of ultraviolet radiation, will vary with their increase and decrease. The increase we should expect in the higher latitudes, where the auroral discharges occur. The equator to pole circulation of the upper atmosphere, and the paralleling of magnetic lines of force by auroral discharges, might very well lead to a greater amount of ozone in the upper air of temperate and polar regions than in that of the tropics."

The amount of ozone found in the air we breathe has repeatedly been estimated to amount to more than 1 part in 700,000 parts air. The effect of ozone on the respiratory organs has again lately been investigated. Jordan and Carlson ${ }^{23}$ summarize the results of their research work, in part, as follows: "Human beings are injuriously affected by amounts of ozone far less than are necessary to produce bactericidal effect, and there is no evidence for supposing that a quantity

21. Lenard, P., and Ramsauer, C.: Sitzungsberichte der Heidelberger Academie der Wissenschaften, Abh. 24, 1911, p. 42.

22. Humphreys, W. J.: Astrophysical J. 32: No. 2.

23. Jordan, E. O., and Carlson, A. J.: Ozone, J. A. M. A. 61:1007 (Sept. 27) 1913. 
of ozone than can be tolerated by man, has the least germicidal action. In concentrations that appreciably affect man, ozone appears to have uniformly an injurious action. This action is primarily on the respiratory passages-irritation of the sensory nerve endings, and irritation, corrosion and depression of the epithelial cells. The depression and drowsiness produced by ozone are due to the intense irritation of sensory nerve endings (vasomotor effect) in the respiratory tract, as well as to the secondary effects of the change in the activity of the aveolar epithelium. Nor can we accept the suggestion of Hill and Flack, that small amounts of ozone may be of therapeutic value in certain diseases of the respiratory tract by reason of the hyperemia following the ozone irritation. The ozone irritation leads to intense hyperemia of the respiratory tract, . . . The cells injured by ozone are probably more readily invaded by bacteria and have less than normal power of healing clespite the hyperemia. The physiology of ozone points to the conclusion that the use of this poisonous gas as a therapeutic agent is either valueless or injurious." As these authors say: "The cardiac and vasomotor changes on exposure to ozone have not been extensively studied." "Here we have as an effect of exposure to ozone, generally considered harmless, symptoms as headache, sore throat, pain in the chest, intense irritation of the respiratory tract, and even if prolonged exposure to ozone should prove harmless to the robust person, what about the unfortunate person whose lungs have only slight power of resistance? Concentrations of ozone of 1 part per million parts of air are certainly injurious, but it does not follow that the weaker concentrations of ozone are proportionately injurious."

In addition to this research work we should consider the "studies of the respiratory inflammatory processes initiated by the inhalation of toxic gases" (used in modern warfare) made by Winternitz, Wason and McNamara. ${ }^{24}$ They state that "the pathology produced by the inhalation of these poisonous vapors is analogous to that found in influenzal pneumonia." Their conclusions contain the following: "A basis for the interpretation of the respiratory lesions of influenza is offered by the analogous changes in the respiratory tract initiated by the inhalation of poisonous gases. The respiratory lesions are dependent primarily on the damage produced by the true etiologic agent and the systemic capacity to compensate, and only secondarily on invasion by the bacterial flora of the mouth and inspired air."

These findings gain in importance by the general agreement of clinicians that the influenza infection is carried directly into the respiratory tract. D. Symmers ${ }^{25}$ concludes thus; "From the opportunity

24. Winternitz, Wason and McNamara: The Pathology of Influenza, Yale University Press, 1920.

25. Symmers, D.: J. A. M. A. 71:1482 (Nov. 2) 1918. 
that I have had to observe at necropsy and in the living patient, it appears to me to be probable that the prevailing pandemic of influenza is attended by pneumonic lesions from the beginning. Moreover, the distribution of the pathologic changes in the lungs is such as to suggest that the infection is introduced by way of the respiratory tract. . . . In those cases in which death has occurred twenty-four or thirty-six hours after the development of detectable pneumonic signs, it is scarcely conceivable that the massive solidification of the lungs could have taken place with corresponding rapidity. The suggestion naturally follows, that every case of pandemic influenza should be regarded from the outset as pneumonic."

Park ${ }^{26}$ writes: "Epidemic influenza is a disease primarily attacking the respiratory tract." Conner ${ }^{27}$ writes: "In the present epidemic there has been, for all practical purposes, only a single type-the respiratory." Kinsella ${ }^{28}$ says: "Whatever the cause of the disease may be, it is clear that this agent is one to which the body is not accustomed." McLaughlin ${ }^{29}$ concludes: "These indications suggesteither that in the great pandemic we were dealing with a new and entirely different disease, or that the immunity conferred by an attack, if any, was of a very fleeting character." Of course we could not acquire immunity from exposure to an irritating gas similar to ozone. The great clinician Ziemssen wrote many years ago, alluding to epidemics of influenza: "After all we cannot but assume that there must be general conditions, which appear and disappear simultaneously in great expanse of space. Of what nature these influences may be is perfectly dark. We would not be forced to think of miasm or contagion. We are more led to believe that fluctuations of other conditions, extending over great areas of the surface of our globe at the same time furnish an analogy."

\section{CONCLUSIONS}

In conclusion we should consider the following facts:

1. The assumption, that the propagation of influenza is analogous to that of an infectious disease, has so far no foundation in fact. We have no proof that influenza is caused by bacterial infection. The cause of influenza is still unknown. We have not succeeded in inoculating influenza from person to person; we cannot transmit it experimentally. A "drop infection" from person to person has likewise not been proved. Frost ${ }^{30}$ believes in "contact in the broad sense" and

\footnotetext{
26. Park. W. H.: J. A. M. A. 73:318 (Aug. 2) 1919.

27. Conner, L. A.: J. A. M. A. 73:321 (Aug. 2) 1919.

28. Kinsella, R. A.: J. A. M. A. 72:717 (March 8) 1919.

29. McLaughlin, A. T.: The Shattuck Lecture, Boston M. \& S. J., July 1, 1920.

30. Frost, W. H.: J. A. M. A. 73:313 (Aug. 2) 1919.
} 
adds: "As regards preventive measures, the efficacy of those carried out-is not proved." Howard and Love ${ }^{31}$ state that, "in U. S. Army Camps, where all accepted measures for the prevention of the spread of respiratory disease (during the pandemic) were vigorously enforced, the incidence of the disease apparently was as great as in other camps where such measures were less rigidly and effectively applied." Transmission of influenza is more logically explained by an air which may carry in infective virus or a poisonous gas, an animate or an inanimate agent, into our lungs and which naturally has free access everywhere. We cannot guard ourselves against such air, except by masks, which would nullify the bad effect of such air. The research work describing the effect of inhalation of ozone and warfare gas proves that the pathology of influenza can readily be explained by the assumption that a poisonous gas is the cause of the pandemic.

2. Atmospheric conditions that are characteristic, we could as well say pathognomonic, for influenza and its spread are well defined. The cycles in which the pandemics alternate with periods of relative quiescence are distinctly covered by the cycles of high air pressure periods during and before the pandemics and of low air pressure periods following them.

3. The first appearance of influenza cases in a pandemic, and the full development of the latter, are geographically in direct relation to the appearance and development of certain anticyclonic conditions. The successive seizure of great districts of the continent invariably originates in one or the other center of great anticyclonic action on the globe, as in inner Asia, Bokhara, and in Canada during the 1890 pandemic, and as in the region of the "Canary Island High" (Spanish influenza), and in Canada during the 1918 pandemic.

4. The influenza pandemic extends, spreads in the same direction and with the same velocity as the great anticyclone spreads from its center over a continent. In the United States therefore, it generally attacks first those districts that lie in the path of the Alberta type or the Hudson Bay type.

5. The prepandemic weather, as the charts prove, remains for a long period free from any cyclonic action. It is the forerunner of the coming avalanche of atmosphere.

6. Increases of influenza morbidity preceding a great pandemic are always in harmony with similar increases of an anticyclonic type of weather.

7. As the period of very high pressure of from 1830 to 1840 was synchronous with the greatest pandemic before our times, similarly, the 1890 and 1918 pandemics were heralded by an ever increasing air

31. Howard and Love: Influenza, Mil. Surg. 46:522 (May) 1920. 
pressure since 1878, reaching the highest figures only during the period of the last pandemic, as the Bismarck pressure line so well illustrates in Figure 1.

8. The anticyclonic weather conditions for some weeks before and during the prevalence of a pandemic are almost stereotyped for every city on the charts. The usual type for the United States is the Alberta type. The gigantic masses of air that it whirls and spreads over the country in a southerly and easterly direction with the velocity of a fast train, are represented by the more or less extreme positive departures of the air pressure from normal in the most typical manner in every city. Distinct cyclonic action is, then, missing in every single instance, and the only type in evidence is prolonged high pressure for a longer period, as in September and October, 1918, or for a shorter period of highest air pressure, as in January, 1920.

9. Likewise, we find in a stereotypic fashion the beginning of a decrease of morbidity in every city following the first well marked cyclonic action. As the anticyclonic period is common to the entire United States, proportionate only to the time necessary for the spread of its masses of air, likewise, the cyclonic action, when it arrives, puts its stamp on every city almost on the same day.

10. Extraordinary proof of the interdependence of the pandemic and an extreme high pressure period occurs in January, 1920. The beginning of both is clearly defined and the decrease of morbidity appears in direct relation to cyclonic action, beginning in the first week of February.

11. This interdependence gains additional value by the research work on prolonged exposure to ozone and other poisonous gases and the injury to the respiratory tract caused thereby. In fact, it is clear that the symptoms caused by inhalation of such poisonous gases resemble the influenza symptoms perfectly.

12. We have reason to assume that air of some anticyclones contains ozone in unusual quantity as a product of unusual solar output. If we hesitate to deduce that ozone is causative of influenza because its odor and the gas itself has not been detected in the air we breathe during a pandemic, we must admit that no attempt has been made to find it.

Of course some degree of speculation cannot be avoided if we seek for any theory to guide us in the labyrinth of influenza. The possibility of its spread by the atmosphere is consistent with the facts. It has the merit that it leads us to an experimental study of the air, and it gives us ozone as a guide. A second Schoenbein may arise and find a chemical body, similar to ozone, or we may extend Haldane's research work, which suggested that the rate of supply of oxygen to 
the tissues by the blood in the systemic capillaries in the lungs is insufficient in influenza for the normal processes of life.

We cannot, after the presentation of the foregoing facts, escape our duty to demand a critical analysis of the air during the different air pressure conditions and especially during the epidemics of the respiratory organs. Furthermore, we have achieved the very important practical gain that we may predict an increase in pneumonia morbidity whenever an extensive anticyclone is approaching any territory in question, and we have a warning of a coming explosiveness of morbidity in general whenever the magnitude of the approaching anticyclone warrants it. The necessary information, easily given by the Weather Bureau, would make a suitable preparedness possible to meet the emergency. A failure to recognize this fact would seem to involve a great responsibility.

\section{Spirochetal Pllmonary Gangrene}

Drs. Fishberg and Kline, authors of the paper with the above title, published in the Arcinives of Internal Medicine, January 15, 1921, p. 61, request the addition of the following paragraph to their paper:

The occurrence of fusiform bacilli and spirochetes, not only in the exudate over the gums but also in the gangrenous lung tissue, lends support to the belief that this is a case of aspiration pneumonia followed by pulmonary gangrene in which innumerable mouth organisms, Vincent's spirochetes and fusiform bacilli from the gingivitis were aspirated into the lungs, the mouth organisms producing the widespread consolidation and the spirochetes the associated gangrene. 